\section{Comparative analysis of perceptual evaluation, acoustic analysis and indirect laryngoscopy for vocal assessment of a population with vocal complaint}

\author{
Kátia Nemr ${ }^{1}$, Ali Amar ${ }^{2}$, Marcio Abrahão ${ }^{3}$, Grazielle \\ Capatto de Almeida Leite ${ }^{4}$, Juliana Köhle ${ }^{5}$, Alex an- \\ dra de 0. Santos ${ }^{6}$, Luiz Artur Costa Correa
}

Key words: evaluation, voice, spectrum analysis, laryngoscopy, speech, language and hearing pathology.

\section{Summary}

\begin{abstract}
A a result of technology evolution and development, methods of voice evaluation have changed both in medical and speech and language pathology practice. Aim: To relate the results of perceptual evaluation, acoustic analysis and medical evaluation in the diagnosis of vocal and/or laryngeal affections of the population with vocal complaint. Study Design: Clinical prospective. Material and Method: 29 people that attended vocal health protection campaign were evaluated. They were submitted to perceptual evaluation (AFPA), acoustic analysis (AA), indirect laryngoscopy (LI) and telelaryngoscopy (TL). Results: Correlations between medical and speech language pathology evaluation methods were established, verifying possible statistical signification with the application of Fischer Exact Test. There were statistically significant results in the correlation between AFPA and LI, AFPA and TL, LI and TL. Conclusion: This research study conducted in a vocal health protection campaign presented correlations between speech language pathology evaluation and perceptual evaluation and clinical evaluation, as well as between vocal affection and/or laryngeal medical exams.
\end{abstract}

Ph.D. in Social Psychology, USP. Responsible for the Service of Speech and Hearing Pathology, Hospital Heliópolis.

2 Master in Head and Neck Surgery, HOSPHEL. Head and Neck Surgeon, Hospital Heliópolis.

3 Full Professor, Head and Neck Surgery, UNIFESP. Head of the Discipline of Head and Neck Surgery, UNIFESP.

${ }^{4}$ Master studies under course, Program of Post-graduation Studies in Speech and Hearing Pathology, PUC/SP, Specialist in Voice, Irmandade da Santa Casa de Misericórdia de São Paulo. Speech and Hearing Pathologist, Service of Speech and Hearing Pathology, Hospital Heliópolis.

${ }^{5}$ Specialist in Voice, CEFAC/SP. Speech and Hearing Pathologist, Service of Speech and Hearing Pathology, Hospital Heliópolis. ${ }^{6}$ Specialist in Oral Motricity, CEFAC/SP. Speech and Hearing Pathologist, Service of Speech and Hearing Pathology, Hospital Heliópolis. ${ }^{7}$ Master studies in Health Sciences, Hospital Heliópolis. Head and Neck Surgeon, Hospital Heliópolis. Affiliation: Hospital Heliópolis Sao Paulo, SP.

Address correspondence to: Kátia Nemr - Rua Cincinato Braga 463 ap. 82 01333-011 Bela Vista, Sao Paulo, SP.

Tel (55 11) 9217-1111 / (55 11) 6215-2837 - E-mail: knemr@uol.com. br

Article submited on September 13, 2004. Article accepted on November 10, 2004. 


\section{INTRODUCTION}

The larynx is an important muscle-cartilaginous muscle whose functions are sound production, breathing and sphincter action, normally affected in diseases that are manifested as dysphonia.

Throughout the years, vocal assessment has been a subject of constant improvement by Speech and Hearing Pathology and O torhinolaryngology and Head and Neck Surgery. Currently, subjective and objective criteria are part of the convergence of all assessment criteria.

Among the examples of diagnostic tools used to define laryngeal diseases we can include indirect laryngoscopy (Garcia's mirror), telelaryngoscopy (rigid endoscopy) and nasofibrolaryngoscopy (flexible endoscopy).

As to vocal assessment, it includes perceptual voice assessment and computer acoustic analysis.

Perceptual voice assessment of vocal function started in the $19^{\text {th }}$ century by subjectively assessing the voice with the human ear as assessment instrument. This practice has been used to present to detect affections, trying to identify the balance betw een what is seen and heard in the subject of the analysis and interp retation of findings, in which we learn and understand the individual dynamics of each one with their own voice and communication characteristics ${ }^{1}$.

As a result of instrument evolution, acoustic analysis was devised, which is a way to objectively assess voice; the advantages of this method are increase in diagnostic precision, identification and documentation of short and long-term treatment efficacy and possibility of providing visual feedback to the patient ${ }^{2}$.

Despite the advantages of acoustic analysis, it does not provide diagnosis, but it works as a complement to vocal assessment, together with physiological findings from the physical examination conducted by the physician and perceptual vocal analysis ${ }^{3}$. It is important to highlight that acoustic analysis is a complementary test that does not replace clinical assessment conducted by the speech and voice therapist, but it rather serves as another resource to help assessment.

All previously referred assessment methods, be them conducted by the physician or voice therapist, seem to be complementary in understanding and defining the management of cases that have vocal affections, which means that interdisciplinary approach is essential for successful resolution of cases. How ever, in view of the growing demand for vocal health protection actions, such as awareness campaigns and vocal problem prevention efforts, the discussion on the most appropriate methods to efficiently support these actions becomes more necessary.

The purpose of the present study was to relate results of perceptual voice assessment, acoustic analysis and medical assessment with the diagnosis of vocal and/or laryngeal affections in subjects with vocal complaints seen in a vocal health protection campaign.

\section{MATERIAL AND METHOD}

The vocal health protection campaign was organized by the Service of Speech and Hearing Therapy, Hospital Heliópolis, together with Head and Neck Surgery and PostGraduation Course on Health Sciences - HOSPHEL, counting on a team of speech and voice therapists, physicians and oro-maxillo-facial surgeons for one-day activities in which they assessed 80 subjects.

Inclusion criteria:

a) all subjects had some vocal complaint.

Exclusion criteria:

a) all subjects that presented other non-vocal complaint, with or without previous diagnosis.

b) any subject that could not or refuse to undergo any of the assessment methods.

O ut of a total of 49 subjects with vocal complaints, 20 were excluded for not having conducted the exams. The sample comprised 29 subjects, 20 women and 9 men, aged 12 to 70 years, mean age of 44 years. The most important complaints were: hoarseness in 10 subjects (34\%); difficulty to produce voice (such as abnormalities, voice breaks or vocal loss) in 9 subjects (31\%); sore throat in 4 subjects (14\%); vocal fatigue in 3 subjects (10\%); other complaints (throat irritation, choking, short of breath) in 3 subjects (10\%).

The method was divided into 4 stages:

Stage 1 - Perceptual voice assessment (AFPA), based on scale RASAT ${ }^{4,5}$. The protocol led us to pointing no vocal affection (when all assessed criteria were within the normal range); or presence of vocal affection, regardless of grade or type of affection. The assessment comprised a sample of vowel production, number counting (1 to 10 ) and connected speech.

Stage 2 - Acoustic record of the voice using acoustic analysis software (AA) GRAM 5. 1. 7 by specially trained speech therapist (spectrogram version 5. 1. 7. R. S. Horne - available at www. monumental. com/ rshorne/gram. html) and vocal recording in the $\mathrm{PC}$ and in cassette tapes (Panasonic tape recorder model RN-302). Subjects were asked to produce prolonged vowel / $a /$ and to count from 1 to 10 . Vocal spectrum were later analyzed by two professionals from the speech and vocal therapy team of the center, who had been specifically trained in the software, and the final result was the consensus of both analyses, considering vocal related aspects (general regularity of tracing, quality of harmonic recording, presence of interruptions, modulations and bifurcations, 
number of harmonics, presence of noise among the harmonics, replacement of harmonics by noise) ${ }^{6}$. We considered spectrum with and without affection, regardless of the type or grade of affection. The examiners did not have access to each others' results of the assessment protocol nor to recorded voices during the procedure.

Stage 3 - Conduction of indirect laryngoscopy with Garcia's mirror (LI) by physicians of the Service of Head and Neck.

Stage 4 - Conduction of telelaryngoscopy (TL) by two surgeons of the team of head and neck surgery of Hospital Heliópolis. This exam was conducted in a different date from the others, with previous scheduling.

In the medical exams described in stages 3 and 4 we considered the following findings: no affection (in cases in which no affection or visible abnormality was observed in the laryn $\mathrm{x}$ ) or presence of affection (in cases in which we observed affection or visible abnormality in the larynx, regardless of being irritative, functional or structural).

Each subject received a Manual of Vocal Guidance given by a speech and voice therapist ${ }^{7}$ (Nemr, Carvalho, Köhle 2002) in addition to guidance compatible with their cases, and referral to other assessments and/or vocal therapy, if necessary.

We defined the correlations between the assessment methods described in stages 1, 2, 3 and 4. The statistical analysis used Fischer Exact Test, considering significant $p$ value equal or below 0.05 .

Project № 230 and the Free Informed Consent of this study were approved by the Research Ethics Committee of the Institution.

\section{RESULTS}

This study gathered 29 subjects. AFPA was affected in 22 subjects whereas AA was detected in 17, and 14 of them were assessed. TL was abnormal in 19 subjects.
Among the 7 subjects with abnormal AFPA, 2 had abnormal TL whereas there were 12 subjects with normal $\mathrm{AA}$, and 7 had abnormal TL.

AFPA results were in agreement with AA in $62 \%$ of the cases, but AFPA showed higher correlation with the TL findings; in $77 \%$ of the cases there were abnormalities in both $(p=0.03)$.

Table 1 shows the correlation between the three assessments conducted in absolute numbers.

Despite the presence of vocal symptoms, there was no affection identified in assessments conducted in $4(13 \%)$ subjects. In other 4 cases, the abnormalities observed in AFPA and AA were not related with TL affection.

Among the 19 subjects that presented TL abnormalities, 15 (79\%) had affections detected in LI.

\section{DISCUSSION}

The importance of vocal dynamic global assessment with auditory and visual aspects reinforces the relevance of this assessment method in speech and vocal practice, given it also considers body expression of dysphonia in complementation of vocal findings.

We should emphasize that in the studied sample, all subjects presented vocal complaints and high level of agreement between AFPA and medical exams, which showed positive association between them.

AFPA presented divergence between each speech and vocal therapist that analyzed the voice of subjects owing to professional formation, experience and especially auditory training of each of them. Some authors refer that even among trained professionals conducting this assessment, it is observed that in comparison to the diagnosis, the perceptual assessment presents low discrimination skill and low reliability to define normal range or vocal abnormalities ${ }^{8}$. However, it is an important method and still today it is used in practice 9 . In the present study, AFPA proved to be a valuable method given the agreement betw een AFPA and TL was $76 \%$.

Interobserver studies should be developed to assess the level of agreement between examiners, a topic

Table 1. Relationship between AFPA, AA and TL

\begin{tabular}{|c|c|c|c|c|c|c|}
\hline & & & \multicolumn{4}{|c|}{$\mathrm{TL}$} \\
\hline & & & & no affections & with affections & Total \\
\hline \multirow{5}{*}{ AFPA } & \multirow{2}{*}{ no affections } & \multirow[b]{2}{*}{ AA } & no affections & 4 & 0 & 4 \\
\hline & & & with affections & 1 & 2 & 3 \\
\hline & \multirow{2}{*}{ with affections } & \multirow{2}{*}{$\mathbf{A A}$} & no affections & 1 & 7 & 8 \\
\hline & & & with affections & 4 & 10 & 14 \\
\hline & & & Total & 10 & 19 & 29 \\
\hline
\end{tabular}

Legend:

AFPA - perceptual voice analysis

AA - acoustic analysis

TL - telelaryngoscopy 
developed in some medical areas ${ }^{10-12}$. In our area, there are some studies along these lines, especially on interobserver assessment with different levels of knowledge and professional experience, as well as professionals from different countries; however, the authors did not find high levels of disagreement, pointing to perceptual scale as an excellent clinical instrument ${ }^{13,14}$.

We should consider that in view of vocal complaint and/or abnormalities in one of the assessment, the subject should be further investigated. We observed that out of the total of cases that presented TL affections, $10 \%$ had no repercussion in AFPA. In cases of initial neoplasm of supraglottis and hypopharynx, for example, there may not be signals of perceptual auditory abnormality. In such cases, isolated perceptual assessment, in view of vocal complaint, may underestimate the severity of a subject, who should be referred to medical assessment.

Conversely, in some cases, abnormalities observed in AFPA were not confirmed by LI (24\%) or TL (17\%). In such cases, we should not disregard the possibilities of minor structural alterations of the vocal folds that can be diagnosed by stroboscopy; even if not present in most specialized clinics, it provides important information about the vibration cycle or pattern (dynamic characteristics of vocal fold mucosa), and the value of fundamental frequency ${ }^{15-17}$. However, laryngostroboscopy may also have limitations such as the possibility of not detecting minor structural alterations in the exam ${ }^{18}$. About $30 \%$ of minor structural alterations are diagnosed only at the surgical act ${ }^{15}$.

The literature points to indirect laryngoscopy as a very useful method to initially detect diseases 5,19 . Even though there may be difficulties to detect minimum alterations, LI allows the exclusion of severe diseases that may be present without vocal affections.

Since AA is a highly sensitive method, some affections were not confirmed by the other assessment methods. In a study conducted with a population without vocal complaints, there were affections to acoustic parameters in all cases that presented some variation from the normal range, emphasizing acoustic analysis as a sensitive method ${ }^{20}$. This assessment is a valuable instrument in speech and vocal practice, both as visual aid to the patient to follow up phonotherapy progression, and in scientific research studies and in complementing speech and voice assessment 2,3 . Some authors state that AA does not replace perceptual assessment in clinical practice, being complementary methods ${ }^{21}$.

In $14 \%$ of the cases in which voice and speech abnormalities were detected but not confirmed in TL we may correlate it with the fact of they having being conducted on different days. If on the screening day the subject had a cold, for example, which had disappeared by the day of the telelaryngoscopy, there would definitely be differences in the results, a fact that should be taken into account in future studies.
In the literature, many studies discussed the efficacy or inefficiency of these diagnostic methods; however, it seems to be a consensus the need to associate one more method with more precise knowledge of vocal dynamic and laryngeal conditions, especially in cases of vocal complaint ${ }^{22-24}$. Therefore, the findings in the present study reinforce the idea that the association of more than one method supports vocal assessment, especially the association of perceptual assessment with indirect laryngoscopy or telelaryngoscopy.

\section{CONCLUSON}

This study conducted in a vocal health protection campaign with the population reporting vocal complaints showed agreement between perceptual assessment and medical assessment in the diagnosis of vocal and/or laryngeal abnormalities. Acoustic analysis is a complementary method that may be useful in the assessment of subjects with vocal complaints.

\section{REFERENCES}

1. Ferreira LP, Algodoal MJ, Andrada e Silva MA. Avaliação da voz na visão (e no ouvido) do Fonoaudiólogo: saber o que se procura para entender o que se acha. In: Marchesan IQ, Zorzi JL, Gomes ICD. Tópicos em fonoaudiologia 1997/1998. São Paulo: Lovise; 1998. p. 393-413.

2. Carrara de Angelis E, Cervantes $O$, Abrahão M. Necessidade de medidas objetivas da função vocal: avaliação acústica da voz. In: Ferreira LP, Costa HO. Voz ativa falando sobre a clínica fonoaudiológica. São Paulo: Rocca; 2001. p. 53-72.

3. Casmerides MCB, Costa HO. Laboratório computadorizado de voz: caracterização de um grupo de usuários. In: Ferreira LP, Costa HO. Voz ativa falando sobre a clínica fonoaudiológica. São Paulo: Rocca; 2001: 263-79.

4. Pinho SMR, Pontes P. Escala de avaliação perceptiva da fonte glótica: RASAT. Vox Brasilis; 2002.

5. Pinho SMR. Avaliação e tratamento da voz. In: Pinho SMR. Fundamentos em fonoaudiologia tratando os distúrbios da voz. Rio de Janeiro: Guanabara Koogan; 1998. p. 1-37.

6. Behlau M. Aprofundamento GRAM 5. 1. São Paulo; 2002.

7. Nemr K, Carvalho M, Köhle J. Manual de orientação vocal. São Paulo: Gráfica do Hospital Heliópolis; 2002.

8. Dornelles S, Jotz GP, Guilherme A. Capacidade discriminatória e confiabilidade da análise perceptiva auditiva da voz de crianças institucionalizadas. In: Ferreira LP, Costa HO. Voz ativa falando sobre a clínica fonoaudiológica. São Paulo: Rocca; 2001. p. 167-81.

9. Dejonckere PH, Remacle M, Fresnel-Elbaz E, Woisard V, CrevierBuchman L, Millet B. Differentiated perceptual evaluation of pathological voice quality: reliability and correlations with acoustic measurements. Rev Laryngol Otol Rhinol 1996; 117(3):219-24.

10. Hermans R, Feron M, Bellon E, Dupont P, Bogaert WVD, Baert $A L$. Laryngeal tumor volume measurements determined with $C T$ : a study on intra- and interobserver variability. I. J. Radiation Oncology Biol Phys 1998; 40(3):553-7.

11. Paiva RGS, Souza RP, Rapoport A, Soares AH. Avaliação por tomografia computadorizada do envolvimento loco-regional do carcinoma espinocelular de corda vocal. Radiol Bras 2001; 34 (4): 193-200.

12. Andrade JM, Perone AA, Souza RP, Rapoport A. Avaliação da concordância interobservadores na analise da extensão dos tumores do espaço protídeo por meio de tomografia computadoriza. Rev Imagem 2002; 24(1):1-7. 
13. De Bodt MS, Wuyts FL, Van de Heyning PH, Croux C. Test-retest study of the GRBAS scale: influence of experience and professional background on perceptual rating of voice quality. J Voice 1997; 11(1):74-80.

14. Yamaguchi $H$, Shrivastav $R$, Andrews $M L$, Niimi S. A comparison of voice quality ratings made by Japanese and American listeners using the GRBAS scale. Folia Phoniatr Logop 2003; 55(3):147-57.

15. Gonçalves MIR. Alterações estruturais mínimas da cobertura de pregas vocais -fatores que interferem no diagnóstico. [tese] São Paulo: Universidade federal de São Paulo; 1994.

16. Pontes PAL, Gadelha MEC, Gonçalves MIR. Alterações estruturais: mínimas da laringe. In: Pinho SMR. Fundamentos em fonoaudiologia tratando os distúrbios da voz. Rio de Janeiro: Koogan; 1998. p. 65-71.

17. Dragone MLOS, Behlau M. Ocorrência de disfonia em professores: fatores relacionados a voz profissional. In: Behlau M. A voz do especialista. Rio de Janeiro: Revinter; 2001.

18. Figueiredo DC, Souza PRF, Gonçalves MIR, Biase NG. Análise perceptivo-auditiva, acústica computadorizada e laringológica da voz de adultos jovens fumante e não-fumantes. Rev Bras Otorrinolaringol 2003; 69 (6): 791-800.
19. Bompet R; Sarvat MA. A importância do trabalho integrado na área de voz. In: Pinho SMR. Fundamentos em fonoaudiologia tratando os distúrbios da voz. Rio de Janeiro: Guanabara Koogan; 1998. p. 41-48.

20. Corazza VR, Silva VFC, Queija DS, Dedivitis RA, Barros APB Correlação entre os achados estroboscópicos, perceptivo-auditivos e acústicos em adultos sem queixa vocal. Rev Bras Otorrinolaringol 2004; 70(1): 30-4.

21. Pereira JGE, Cervantes 0 , Abrahao M, Parente SFA, Carrara de Angelis $\mathrm{E}$. Noise-to-harmonics ratio as an acoustic measure of voice disorders in boys. J Voice 2002; 16(1):28-31.

22. Klein S, Piccirillo JF, Painter C. Student Research Award 1999: comparative contrast of voice measurements. Otolaryngol Head Neck Surg 2000; 123(3):164-9.

23. Lopes Filho O, Bussoloti Filho I, Castro Junior NP, Costa HO. Bases da propedêutica otorrinolaringológica. In: Carvalho MB. Tratado de Cirurgia de Cabeça e Pescoço e Otorrinolaringologia. São Paulo: Editora Atheneu; 2001. p. 3-19.

24. Yu P, Ouaknine M, Revis J, Giovanni A. Objective voice analysis dysphonic patients: a multiparametric protocol including acoustic and aerodynamic measurements. J Voice 2001; 15(4):529-42. 